\title{
FHP PRIZES
}

The FHP Foundation, in an award to the International Society of Technology Assessment in Health Care, has established two prizes in Health Care Technology Assessment for outstanding articles in the International Journal of Technology Assessment in Health Care.

A first prize of $\$ 10,000$ and a second prize of $\$ 5,000$ will be given each year for the next five years. The first awards will be given at the June 1991 Society meeting for articles accepted or published in 1990.

For questions regarding the ISTAHC meeting or the prizes, please write to:

Ms Jan Glover

Program on Humanities and

Technology in Health Care

The University of Texas Health

Science Center at Houston

PO Box 20708

Houston, TX 77225

Tel: (713) 792-5140 


\section{History and Purpose}

In the modern medical world of rapidly diffusing technologies, the International Society of Technology Assessment in Health Care (ISTAHC) was organized to encourage research, education, cooperation and the exchange of information concerning the clinical and social implications of health care technologies, and to foster their optimal utilization. The term technology in this context includes the drugs, devices, and medical and surgical procedures utilized in health care as well as the varied organizational and supportive systems within which health care is provided.

Organized in May 1985, the Society's initial meeting was held in Copenhagen with 60 participants from 16 countries. Society membership is now over 540 with worldwide representation providing global perspectives on technological issues. The ISTAHC 7th Annual Meeting will be in Helsinki, Finland, on 24-26 June 1991.

The Society is primarily concerned with emerging medical technologies as they are developed, produced, disseminated, applied and costed. Major issues of concern include:

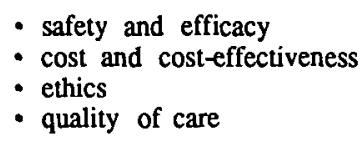

- access to health care

- appropriateness of application

- legal and regulatory considerations

- competing technologies

\section{Society Activities}

To shed light on these important issues which, in turn, will foster and enhance the delivery of quality health care, the Society meets annually and also provides ongoing opportunies such as workshops, conferences and special reports that provide effective international communication and a vibrant exchange of ideas. This intellectual environment is intended to spawn collaborative research on a transnational basis.

\section{Publications}

All ISTAHC members receive the official journal of the Society, the International Journal of Technology Assessment in Health Care, published quarterly by Cambridge University Press, now in its 6th volume. Each issue of the journal provides not only essays on important themes, but also lively columns that give a global perspective on a range of technology-related subjects. This scholarly, peer-reviewed journal welcomes contributions from members and non-members alike, about technology and related health care subjects, including reports and reviews. Members also receive the quarterly ISTAHC Newsletter.

\section{Membership Application/Renewal}

Membership in the Society is open to everyone interested in health care technology and shares the Society's goals. Fill out this form, make out your check or postal money order for US\$70.00 for 1990 dues (\$30) and journal subscription (\$40), payable to Cambridge University Press, and send to the ISTAHC Membership Office listed below. You may also send Visa or MasterCard numbers for payment.

MAILING ADDRESS (IN BLOCK LETTERS PLEASEI) Name

Full Mailing Address

Country

$$
\text { * member profile * * }
$$

Degree(s)

Title/Position

Organization

Principle Interests

Telephone

Mail this application and your 1990 dues payment of US\$70.00 to: ISTAHC Memberahlp Offlce, Cambrldge University Press, 40 West 20th Street, Now York, NY 10011, USA. Make your check or international postal order payable to Cambridge University Press in US funds, or send your Visa or MasterCard number and expiration date. 


\section{International Journal of Technology Assessment in Health Care}

\section{Instructions for Contributors}

The editors welcome submissions of articles which deal with the wide range of topics related to technology assessment in health care - policy, practice, diffusion, economics, ethics, law, and social and cultural perspectives. Authors should send three copies of their manuscript and reserve one copy for their use in checking proofs. Articles must be in English. Spelling, capitalization, and punctuation must be consistent within each article and conform with the 13th Edition of The Chicago Manual of Style (University of Chicago Press). Articles and correspondence should be sent to: Stanley J. Reiser, The University of Texas Health Science Center at Houston, P.O. Box 20708, Houston, Texas 77225, U.S.A.; or Egon Jonsson, The Karolinska Institute and the Swedish Council on Technology Assessment in Health Care, P.O. Box 16158, 10324 Stockholm, Sweden.

Permissions. Submission of an article implies that it has not been published elsewhere. Authors are responsible for obtaining written permission to publish material for which they do not own the copyright. Contributors will be asked to assign their copyrights, on certain conditions, to Cambridge University Press.

Preparation of manuscript. The entire manuscript, including all notes and references, must be typed, double-spaced, on $81 / 2 \times 11$ inch or A4 paper, leaving wide margins for copyediting. Manuscript pages should be numbered consecutively. A manuscript should be arranged as follows: (1) title page, (2) abstract, (3) acknowledgments, (4) text, (5) notes, (6) references, (7) appendix, (8) tables with titles, (9) figures with captions. The title page should list the article title (in capital letters), the lead author's complete mailing address to which proofs will be sent (and telephone number), all authors' names and affiliations, and a short title ( 50 characters or less) for the running head. The abstract cannot exceed 50 words. Any notes to the title or authors and any acknowledgments should be noted on a separate sheet and placed after the abstract.

References and notes. Bibliographic citations in the text are indicated by in-line numbers in parentheses; the numbers in the text correspond to numbers that directly precede each reference.

Text

... Jones and Smith (1) maintained that ...

If more than one reference is cited at a specific place in the text, semicolons should separate each reference number; if page numbers are included, commas should separate each reference number from its page number(s).

Multiple citations without page numbers

... this system has been dealt with at length in the literature $(1 ; 3 ; 12 ; 14)$.

Multiple citation with page numbers

... this system has been dealt with at length $(1,1-10 ; 3,5 ; 12,25-57 ; 14,102-146)$.

Reference (Book)

1. Jones, A. B., \& Smith, J. K. Computer diagnosis and results. New York: Penta Publishers, 1978.

Reference (Journal)

1. Jones, A. B., \& Smith, J. K. The relationship between health needs, the hospital and the patient. Journal of Chronic Diseases, 1985, 32, 310-12.

Reference (Article in edited work)

1. Jones, A. B., \& Smith, J. K. The diagnostic process. In R. Brown \& T. Wilson (eds.), New technology and its medical consequences, vol. 1. New York: Apple Publishers, 1972, 101-34.

The reference list must be in alphabetical order. Titles of journals should not be abbreviated.

When more than a simple source citation is called for, endnotes may be used. Notes should be numbered consecutively throughout the text and typed together on a separate page preceding the reference section. Source citations within notes follow the same parameters of style as citations in text.

Tables and figures. Tables and figures should be numbered consecutively and appear as a unit after the reference section. All tables must be titled; all figures must be captioned. All tables and figures must have at least one text reference, using the following form: "For a different view of this matter, see Table 1 and Figure 3." Table footnotes appear directly after the table body; table source notes follow the footnotes. Figures should be drawn by a professional artist or computer-generated on a Laser printer. The publisher cannot redraw any figure unless the author pays for the cost of such work. All figures should remain legible at a $50 \%$ reduction in size.

Copyediting and proofreading. The publishers reserve the right to copyedit and proofread all articles accepted for publication, but the lead author will be asked to review the copyediting if changes have been substantial. Page proof of a Special Section or General article will be sent to the lead author for correction of typographical errors only.

Offprints. The lead author of a Special Section or General article will receive 25 offprints of his/her article free of charge; additional numbers may be purchased if ordered at proof stage. 


\title{
INTERNATIONAL JOURNAL OF TECHNOLOGY ASSESSMENT IN HEALTH CARE
}

\section{Featured Special Sections and Guest Editors in Forthcoming Issues}

\author{
Assessing the Technology of Dentistry \\ Lars E. A. Folke, University of Lund, Sweden \\ Paul Goldhaber, Harvard School of Dental Medicine, U.S.A. \\ The Technology of Prevention \\ Felix F. Gutzwiller, University of Laussanne, Switzerland \\ Jeffrey Koplan, Centers for Disease Control, U.S.A. \\ Technology and Disability \\ John Hutton, University of York, England \\ Jan Pearson, Linköping University, Sweden
}

The Use and Abuse of Routine, Low Cost Technology

Johannes Vang, World Health Organization, Denmark

Industry and the Generation of Technology

Jerome Grossman, New England Medical Center Hospitals, U.S.A.

Judith Kurland, Department of Health and Hospitals, Boston, U.S.A.

Assessing the Technology of Physical Therapy

Margareta af Klinteberg, Gnesta Primary Health Center, Sweden

Nancy T. Watts, Massachusetts General Hospital, Boston, U.S.A.

Obstetric Technology: A Future Perspective

Miriam Orleans, University of Colorado Health Sciences Center, U.S.A.

Elina Hemminki, University of Helsinki, Finland

Technology and Ethics

Arthur L. Caplan, University of Minnesota, U.S.A.

James F. Childress, University of Virginia, U.S.A.

Henrik R. Wulff, Herlev University Hospital, Denmark

Genetic Technology and Health Care

Frederick C. Robbins, Case Western Reserve University, U.S.A.

The Person-Machine Relationship in Health Care

Yadin David, Texas Children's Hospital, U.S.A.

The Assessment of Psychiatry

Lawrence R. Tancredi, University of Texas Health Science Center at Houston, U.S.A.

Assessing Intensive Care

Bernard S. Bloom, University of Pennsylvania, U.S.A.

Dag Lundberg, University of Lund, Sweden

Technology and the Consumer

Per Buch Andreasen, Gentofte University Hospital, Denmark

Ralph Crawshaw, Private Practitioner, Oregon, U.S.A.

Barbara Stocking, King's Fund College, U.K.

Orphan Technologies

Judith L. Wagner, Office of Technology Assessment, U.S.A.

Cambridge University Press

The Edinburgh Building, Shaftesbury Road, Cambridge CB2 2RU, England

40 West 20th Street, New York, NY 10011, U.S.A.

10 Stamford Road, Oakleigh, Melbourne 3166, Australia

Printed in the United States of America 